\title{
Polarimetric ice sounding at P-band: First results
}

\author{
Dall, Jørgen
}

Published in:

2009 IEEE International Geoscience and Remote Sensing Symposium,IGARSS 2009

Link to article, DOI:

10.1109/IGARSS.2009.5418278

Publication date:

2009

Document Version

Publisher's PDF, also known as Version of record

Link back to DTU Orbit

Citation $(A P A)$ :

Dall, J. (2009). Polarimetric ice sounding at P-band: First results. In 2009 IEEE International Geoscience and Remote Sensing Symposium, IGARSS 2009 IEEE. https://doi.org/10.1109/IGARSS.2009.5418278

\section{General rights}

Copyright and moral rights for the publications made accessible in the public portal are retained by the authors and/or other copyright owners and it is a condition of accessing publications that users recognise and abide by the legal requirements associated with these rights.

- Users may download and print one copy of any publication from the public portal for the purpose of private study or research.

- You may not further distribute the material or use it for any profit-making activity or commercial gain

- You may freely distribute the URL identifying the publication in the public portal

If you believe that this document breaches copyright please contact us providing details, and we will remove access to the work immediately and investigate your claim. 


\title{
POLARIMETRIC ICE SOUNDING AT P-BAND: FIRST RESULTS
}

\author{
Jørgen Dall \\ National Space Institute, Technical University of Denmark \\ Ørsteds Plads 348, 2800 Kongens Lyngby, Denmark, email: jd@space.dtu.dk
}

\begin{abstract}
For polar ice sheets valuable stress and strain information can be deduced from the crystal orientation fabric (COF) and its prevailing c-axis alignment. Polarimetric radio echo sounding is a promising technique to measure the anisotropic electromagnetic propagation and reflection properties associated with the COF. In this paper, dualpolarized P-band data acquired with the airborne POLARIS system near the ice divide of the Greenland ice sheet are analyzed. The internal layers in the uppermost few hundred meters of the ice sheet look the same at $\mathrm{HH}$ and $\mathrm{VV}$ polarizations, whereas the layering differs further down. Accordingly, the magnitude of the complex $\mathrm{HH}-\mathrm{VV}$ correlation coefficient decreases with depth and, interestingly, the phase gives evidence of polarization dependent reflection and birefringence effects.
\end{abstract}

Index Terms - Radar, sounding, P-band, polarimetry, birefringence, anisotropic reflection, ice sheets.

\section{INTRODUCTION}

In explaining present ice sheets velocities and in inferring past climate, stress and strain are important parameters. Strain in turn results in formation of a crystal-orientation fabric (COF) characterized by ice crystals having a preferred alignment, e.g. near the ice-divide in Greenland, where the ice is stretched in the direction perpendicular to the ice divide and compressed in the vertical direction, the c-axes change from a random orientation near the surface to a preferred orientation parallel with the ice divide deeper in the ice sheet [1]. Since single ice crystals have a dielectric anisotropy [2], also a COF has anisotropic electromagnetic properties, but they depend on the degree of alignment of the ice crystals [3].

The anisotropic dielectric permittivity leads to two phenomena: birefringence and reflections at abrupt COF changes, which can be observed by polarimetric radio echo sounding (RES). Polarimetric RES has already proved a promising glaciological tool [4], [5], but polarimetric RES data are scarce, as most radar ice sounders operate at a single, fixed polarization. Some systems allow the antenna to be rotated, thereby offering dual polarized multi-pass data, which are not necessarily co-registered in a phase preserving manner. This paper is based on data acquired with the fully POLarimetric Airborne Radar Ice Sounder (POLARIS).

\section{POLARIS RADAR}

POLARIS is a P-band demonstrator developed for ESA by the Technical University of Denmark. The aim is to obtain more knowledge about the electromagnetic properties of the Antarctic ice sheet at P-band and to test novel ice sounding techniques in preparation for a potential spaceborne ice sounding radar [6]. A recent ITU allocation of a $6 \mathrm{MHz}$ radar band at $435 \mathrm{MHz}$ has increased the interest in spacebased sounding of the Earth's ice caps.

POLARIS is a fully polarimetric system [7], [8], characterized by a maximum bandwidth of $85 \mathrm{MHz}$, corresponding to a vertical resolution (in ice) of about $1 \mathrm{~m}$. In order to increase the dynamic range, a shallow/deep sounding approach is adopted, i.e. when necessary, overlapped near-surface and near-bottom windows are covered separately. This is done simultaneously by alternating the receiver gain on a pulse-by-pulse basis.

\section{TEST DATA}

In mid May 2008, a Proof-of-Concept (PoC) campaign was carried out in Greenland with the aim of testing the newly integrated POLARIS system, i.e. the focus was on the system functionality and technical performance, not on the acquisition of science data.

Though POLARIS is a fully polarimetric system, only dual polarized data were acquired simultaneously: $\mathrm{HH}$ polarized data are transmitted and received on a linear polarization parallel to the flight track, while VV data are transmitted and receive on the orthogonal linear polarization. Consequently, polarization synthesis cannot be applied to determine the principal axes of the birefringence like in [4]. Instead, data were acquired from two flight tracks, one perpendicular to the ice divide and one parallel to the ice divide as indicated in Figure 1. Hence, at the cross-over, the $\mathrm{HH}$ data from one flight track are expected 


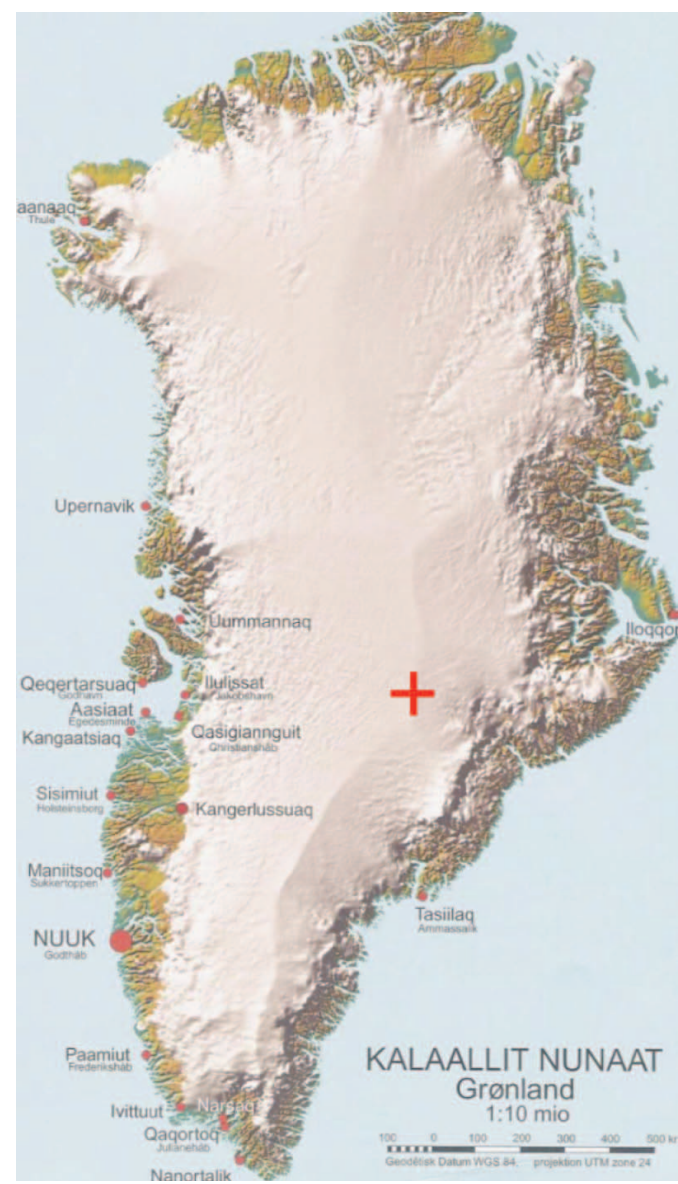

Figure 1 PoC flight tracks (red) at $37^{\circ} 52^{\prime} \mathrm{W}, 69^{\circ} 29^{\prime} \mathrm{N}$.

to be similar to the VV data from the other flight track and vice versa.

\section{RADIOMETRIC ANALYSIS}

The profiles in Figures 2 and 3 show internal layers near the ice divide. By visualizing the relative range derivative $s_{d}\left(n_{r}, n_{a}\right)$ of the multi-looked amplitude data $s\left(n_{r}, n_{a}\right)$ the layers are enhanced (high-pass filtered) and the range attenuation is suppressed (assuming an exponentially attenuated signal). In practice the sample-to-sample difference of the amplitude is computed and divided by the amplitude at the same range

$$
s_{d}\left(n_{r}, n_{a}\right)=\frac{s\left(n_{r}+1, n_{a}\right)-s\left(n_{r}, n_{a}\right)}{s\left(n_{r}, n_{a}\right)}
$$

Here $n_{r}$ and $n_{a}$ are the sample indices in the range and along track directions, respectively. The bright line at the top is the surface echo, and the double bounce echo (surface-aircraft-surface) is seen below the $350 \mathrm{~m}$ marker (the flight altitude was $2000 \mathrm{ft}$ ). The lines above the surface are range sidelobes. The relative range derivative show does not show that the sidelobes are actually suppressed by more than $40 \mathrm{~dB}$ compared with the internal layers just below the ice surface (and much more compared with the surface echo).

When comparing the shallow sounding windows in Figure 2 and 3 it is seen that the layers in the upper half look the same at the $\mathrm{HH}$ and VV polarization unlike those in the lower half of the figures. This dark line under the double bounce reflection is a prominent example..

\section{COHERENCE ANALYSIS}

A quantitative analysis of the anisotropy can be based on the complex VV-HH covariance, or coherence

$$
c_{h h v}\left(n_{r}, n_{a}\right)=\frac{\sum_{s_{h h}\left(n_{r}, n_{a}\right) s_{v v}\left(n_{r}, n_{a}\right)}}{\sqrt{\sum\left|s_{h h}\left(n_{r}, n_{a}\right)\right|^{2}} \sqrt{\sum\left|s_{v v}\left(n_{r}, n_{a}\right)\right|^{2}}}
$$

The magnitude of this coherence is a measure of the similarity of the $\mathrm{HH}$ and VV data, as differences in the local amplitude and phase reduce the coherence amplitude compared to its unity maximum value.

An example of a coherence plot is shown in Figure 4, where it is seen that the coherence is almost maximum for the topmost $200 \mathrm{~m}$ beyond which it drops to about 0.3 and finally increases to about 0.4 . This trend is also seen in the (enhanced) radiometric plots where the polarization in the North-South direction (i.e. VV for EW tracks and HH for NS tracks) has much less contrast at large depths than the East-West polarization has. The fact that the low-contrast channel change when the track angle change shows that the phenomenon is not an artifact associated with the radar.

The phase of the complex coherence is a measure of

- the difference between the reflection coefficients at the two polarizations

- the electrical two-way propagation path length of the $\mathrm{HH}$ and the VV signals.

For an isotropic media the coherence phase is zero, provided the radar is properly calibrated. However, in case of birefringence the speed of light is polarization dependent, and the same physical propagation path corresponds to two different electrical path lengths at the two polarizations.

Figure 2 shows that the coherence phase is zero at the ice surface, but at depths between 500 and $900 \mathrm{~m}$ it has large excursions, which might be due to a phase wrap modulo $2 \pi$. This is also illustrated by the range profile in Figure 3, which is the along-track average of the $2 \mathrm{D}$ phase plot in Figure 2. An attempt to unwrap the phase does not lead to a monotonous phase in this area, whereas data acquired on an EW track a bit further to the west do have a monotonous phase after unwrapping. 


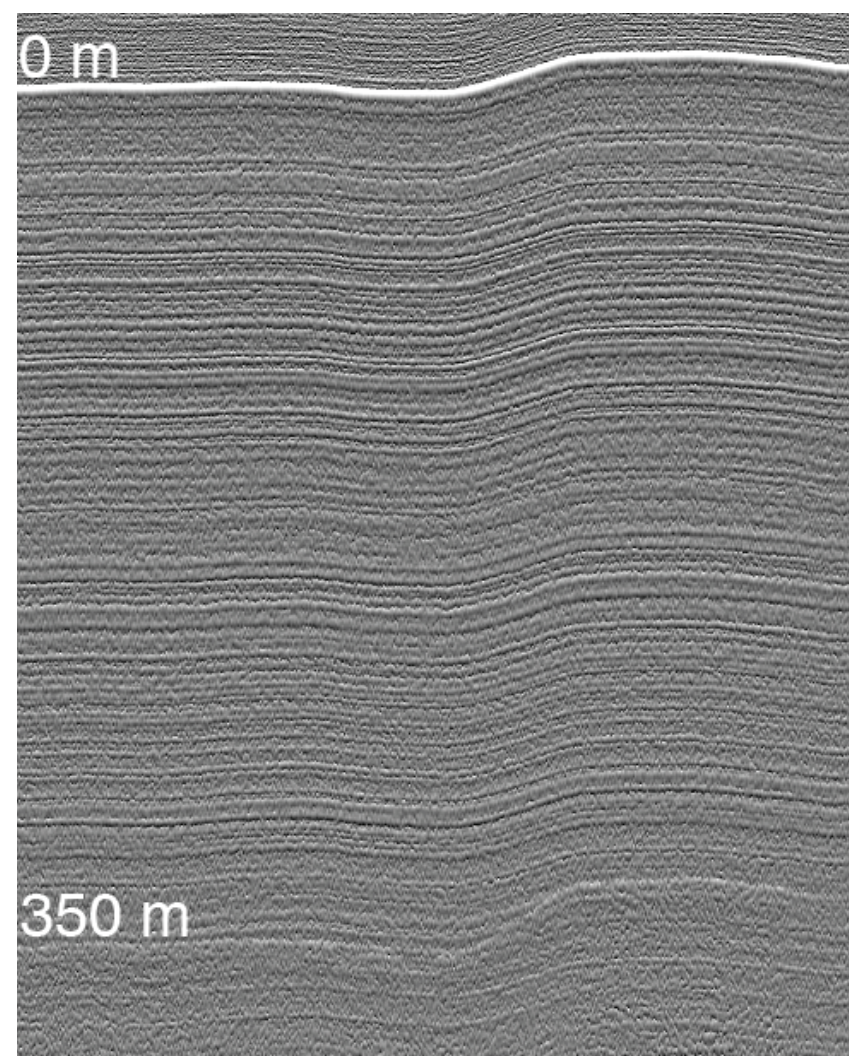

Figure 2 Internal layers mapped at $\mathrm{HH}$ polarization.

In order to verify that the depth variation of the HH-VV phase is not an artifact caused by the radar system the corresponding phase plot has been generated from data acquired on the orthogonal EW track as seen in Figure 4. Since the VV polarization on the NS track is aligned with

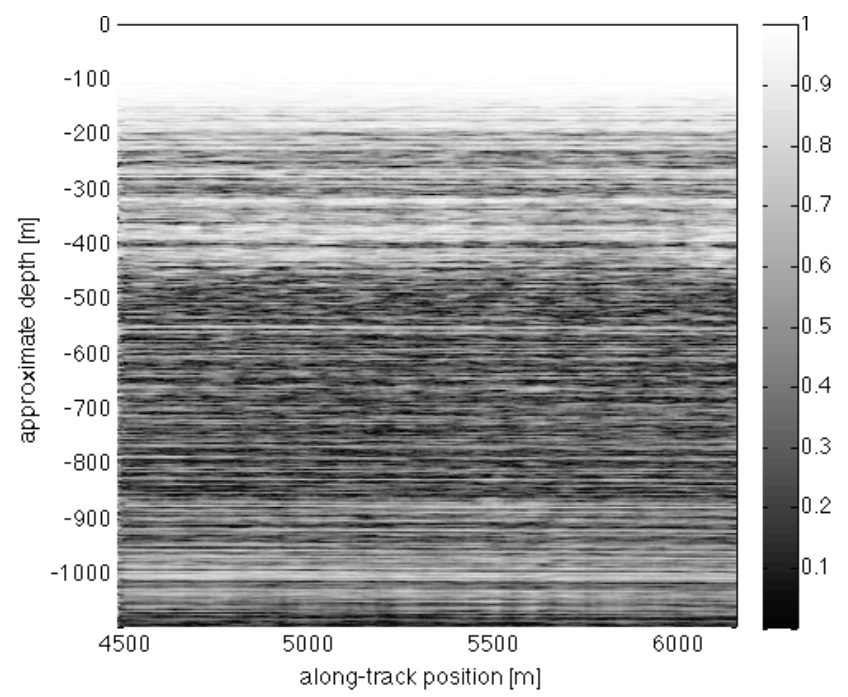

Figure $4 \mathrm{HH}-\mathrm{VV}$ coherence amplitude for the EW track.

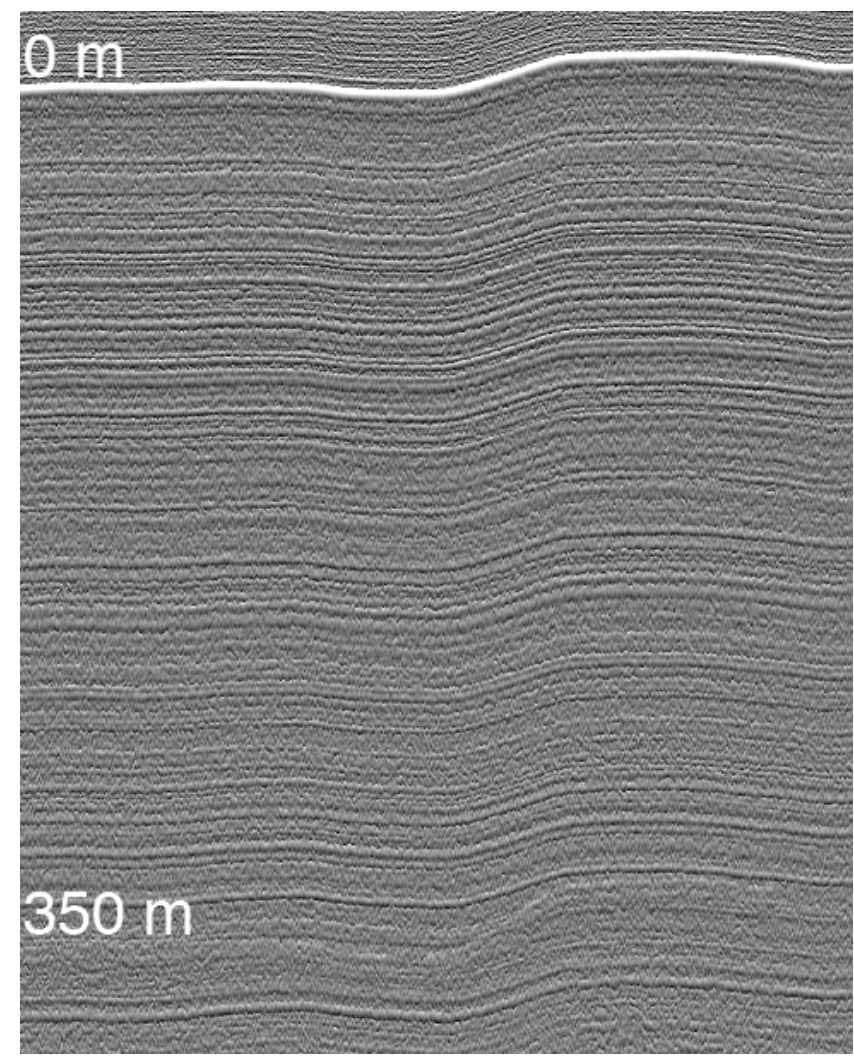

Figure 3 Internal layers mapped at VV polarization.

the $\mathrm{HH}$ polarization on the EW track and vice versa, the phase plots in Figure 3 and Figure 4 are expected to be similar but reversed, which is indeed the case. Hence, the figures are believed to illustrate physics, not an artifact.

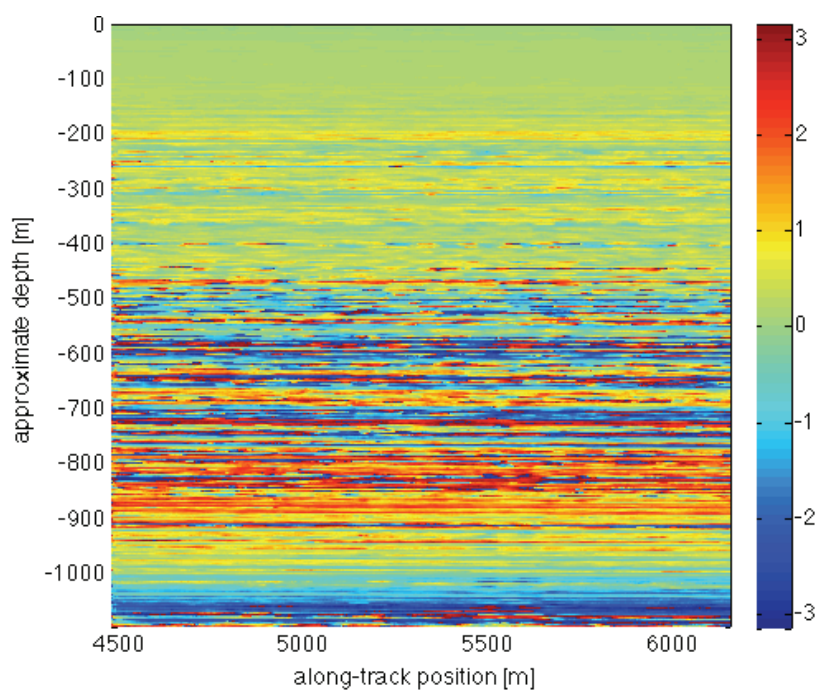

Figure $2 \mathrm{HH}-\mathrm{VV}$ coherence phase for EW track. 


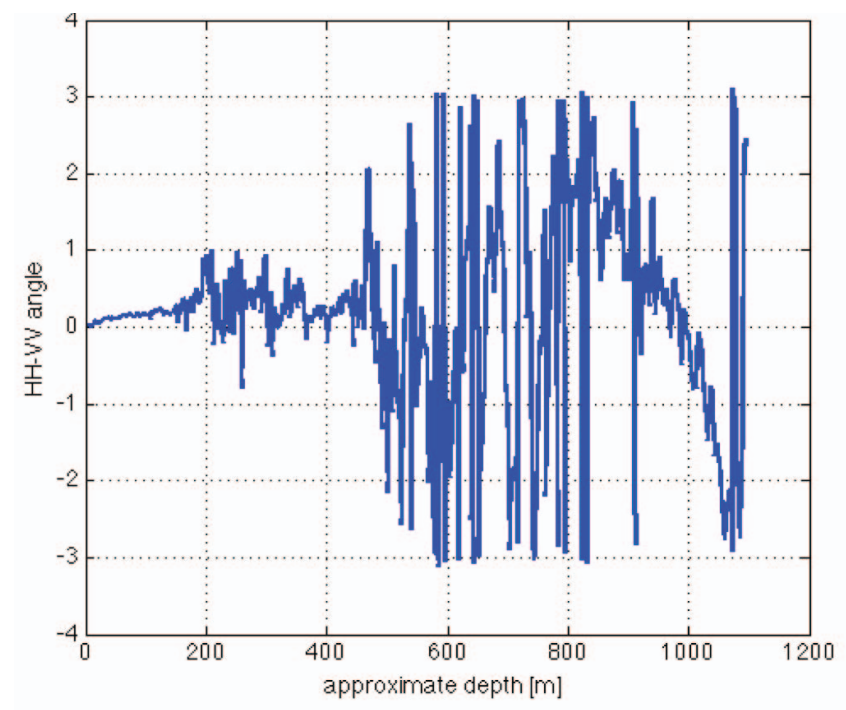

Figure 3 HH-VV coherence phase for NS track.

\section{CONCLUSION}

Two different physical phenomena should be considered in order to explain the observed anisotropy:

- birefringence

- anisotropic reflection

The effect of birefringence is large enough that abrupt COF changes could cause the internal reflections observed [9]. However, stress models and ice core analyses [1] suggest the COF to vary slowly with the depth.

Highly anisotropic internal surfaces are reported for the George VI Ice Shelf [10], where the roughness of the reflecting surfaces is attributed oceanographic processes.

The POLARIS data seem to give evidence of both phenomena. Birefringence-induced propagation effects are seen from the variation of the $\mathrm{HH}-\mathrm{VV}$ phase difference above $500 \mathrm{~m}$ and below $900 \mathrm{~m}$ (after phase unwrapping also in between, though not monotonous). Anisotropic reflection effects could give rise to the internal layering observed.

\section{ACKNOWLEDGEMENTS}

The POLARIS development was primarily financed by the European Space Agency (ESA). The data used in this study were acquired during a Proof-of-Concept campaign, which was part of the instrument development.

Anders Kusk and Steen Savstrup Kristensen, Technical University of Denmark, are acknowledged for the preprocessing of the POLARIS data.

\section{REFERENCES}

[1] Y. Wang, T. Thorsteinsson, J. Kipfstuhl, H. Miller, D. DahlJensen, H. Shoji, "A vertical girdle fabric in the NorthGRIP deep

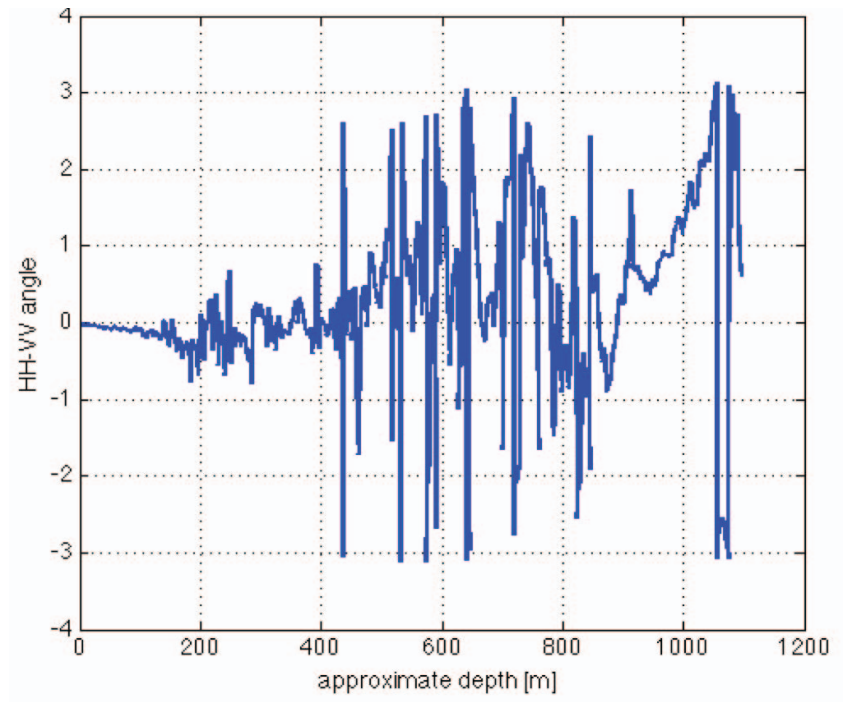

Figure $4 \mathrm{HH}-\mathrm{VV}$ coherence phase for EW track

ice core, North Greenland", Annals of Glaciology, 35, pp. 515-520, 2002.

[2] S. Fujita, S. Mae, T. Matsuoka, "Dielectric anisotroåy in ice Ih at 9.7 GHz", Annals of Glaciology, Vol. 17, pp. 276-280, 1993.

[3] O. Castelnau, H. Thorsteinsson, J. Kipfstuhl, P. Duval, and G.R. Canova, "Modeling fabric development along the GRIP ice core, Central Greenland", Annals of Glaciology, Vol. 23, pp. 194201, 1996.

[4] S. Fujita, H. Maeno, K. Matsuoka, "Radio-wave depolarization and scattering within ice sheets: a matrix-based model to link radar and ice-core measurements and its application”, Journal of Glaciology, Vol. 52, No. 178, 2006.

[5] S. Fujita, T. Matsuoka, T. Ishida, K. Matsuoka, S. Mae, "A summary of the complex dielectric permittivity of ice in the megahertz range and its applications for radar sounding of polar ice sheets", Physics of ice core records, pp. 185-212, 2000.

[6] C.C. Lin, F. Hélière, B. Rommen, C. Buck, N. Floury, M. Davidson, A. Wielders, A., "Airborne and spaceborne ice sounding of Antarctica, Mars, and Europa", Online Proceeding of the $10^{\text {ih }}$ ISAES, USGS Open-file Report 2007-1047.

[7] J. Dall, S.S. Kristensen, V. Krozer, C.C. Hernández, J. Vidkjær, A. Kusk, J. Balling, N. Skou, S.S. Søbjærg, E.L. Christensen, "ESA's polarimetric airborne radar ice sounder (POLARIS): Design and first results", IET Radar, Sonar \& Navigation, submitted January, 2009.

[8] C.C. Hernández, V. Krozer, J. Vidkjær, J. Dall, “Design and performance assessment of an airborne ice sounding radar frontend", Microwave Technology and Techniques Workshop, Noordwijk, 7 pp., 2008.

[9] S. Fujita, S. Mae, "Relation between ice sheet internal radioecho reflections and ice fabric at Miauho Station, Antarctica", Annals of Glaciology, Vol 17, pp. 269-275, 1993.

[10] C.S.M. Doake, H.F.J. Corr and A. Jenkins, "Polarization of radio waves transmitted through Antarctic ice shelves", Annals of Glaciology, Vol. 34, pp. 165-170, 2002. 